\title{
ChemComm
}

\section{Ligand effects of NHC-iridium catalysts for signal amplification by reversible exchange (SABRE) $\dagger$}

\author{
Cite this: Chem. Commun., 2013, \\ 49, 7388 \\ Received 8th May 2013, \\ Accepted 26th June 2013
}

DOI: $10.1039 / c 3 c c 43423 k$

www.rsc.org/chemcomm

\author{
Bram J. A. van Weerdenburg, ${ }^{a}$ Stefan Glöggler, ${ }^{b}$ Nan Eshuis, ${ }^{a}$ \\ A. H. J. (Ton) Engwerda, ${ }^{a}$ Jan M. M. Smits, ${ }^{a}$ René de Gelder, ${ }^{a}$ Stephan Appelt, ${ }^{b c}$ \\ Sybren S. Wymenga, ${ }^{a}$ Marco Tessari, ${ }^{a}$ Martin C. Feiters, ${ }^{* a}$ Bernhard Blümich ${ }^{b}$ and \\ Floris P. J. T. Rutjes ${ }^{a}$
}

\begin{abstract}
SABRE hyperpolarizes substrates by polarization transfer from parahydrogen in a metal complex. We have measured the signal enhancement of pyridine and its exchange rate in various $\left[\operatorname{Ir}(\mathrm{NHC})(\mathrm{Py})_{3}(\mathrm{H})_{2}\right]^{+}$ complexes to gain insight into their dependence on the $\mathrm{N}$-Heterocyclic Carbene (NHC) ligand's steric and electronic properties.
\end{abstract}

Since it was first developed, NMR has become a powerful analytical tool that is now used widely in the fields of chemistry, materials science, and medicine. However, because of the small population differences between the nuclear spin states in a magnetic field, NMR is intrinsically insensitive. One way to overcome this insensitivity is to use hyperpolarization techniques to produce non-Boltzmann spin-state distributions. Para-Hydrogen Induced Polarization (PHIP) can be achieved by a fast hydrogenation reaction with the para-spin isomer of molecular hydrogen $\left(p-\mathrm{H}_{2}\right)$. This has the disadvantage that an unsaturated moiety needs to be present or incorporated into the molecule of interest. ${ }^{1}$

Duckett et al. ${ }^{2}$ have recently reported a new approach, known as Signal Amplification By Reversible Exchange (SABRE), to generate hyperpolarized molecules with $p-\mathrm{H}_{2}$ without direct hydrogenation, thereby expanding the scope of PHIP significantly. In this approach (Fig. 1) hyperpolarization is achieved by the temporary association of a substrate and $p-\mathrm{H}_{2}$ in the coordination sphere of a transition metal, whereupon the polarization

\footnotetext{
${ }^{a}$ Radboud University Nijmegen, Institute for Molecules and Materials, Heyendaalseweg 135, 65625 AJ Nijmegen, The Netherlands. E-mail:m.feiters@science.ru.nl; Fax: +31 2436 53393; Tel: +31 243652016

${ }^{b}$ RWTH Aachen, Institut für Technische und Makromolekulare Chemie, Worringerweg 1, 52074 Aachen, Germany. E-mail: stgloeggler@gmx.de; Tel: +492418020469

${ }^{c}$ Central Institute for Electronics, Research Center Jülich, Wilhelm-Johnen-Straße, 52428 Juelich, Germany. E-mail: st.appelt@fz-juelich.de; Tel: +49 2461613884 $\dagger$ Electronic supplementary information (ESI) available: General procedures, synthetic procedures and determination of the electronic and steric properties, structure determination of the $\mathrm{CO}$ analogues of $\mathbf{3}$ and $\mathbf{4}$, performing SABRE experiments, calculation of enhancement factors, determination of pyridine exchange rates, an overview of experimental data and field dependence of enhancement factors of catalysts. CCDC 945707 and 945708 . For ESI and crystallographic data in CIF or other electronic format see DOI: $10.1039 / \mathrm{c} 3 \mathrm{cc} 43423 \mathrm{k}$
}

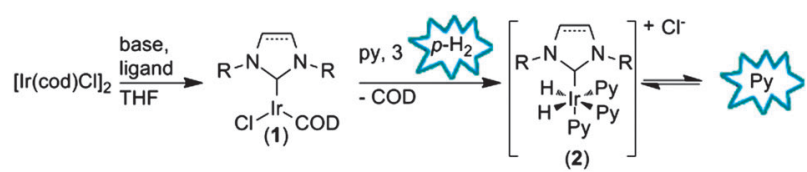

Fig. 1 Formation of active hyperpolarization transfer catalyst 2 from 1 and polarization transfer to pyridine (Py).

can be transferred from the $p-\mathrm{H}_{2}$-derived hydride ligands to the bound substrate via scalar coupling. The hyperpolarized substrate then dissociates into the bulk solution. Since the development of SABRE, several small molecules have been successfully polarized using this technique, ${ }^{3-5}$ and even trace detection is possible in low magnetic fields. ${ }^{6-8}$ The obtained polarization is even large enough for spectroscopy in zero field. ${ }^{9}$ A theoretical report predicts that the efficiency of polarization transfer from $p-\mathrm{H}_{2}$ to the substrate depends on both the magnetic field in which the transfer occurs and the 'lifetime' of the polarization mediating complex. ${ }^{10}$ The lifetime of the metal complex in turn depends on the exchange rates of $p-\mathrm{H}_{2}$ and the substrate in the catalytic complex.

With SABRE, the most commonly used catalyst is Crabtree's catalyst, $\left[\operatorname{Ir}(\mathrm{COD})\left(\mathrm{PCy}_{3}\right)(\mathrm{Py})\right]\left[\mathrm{BF}_{4}\right](\mathrm{COD}=$ cyclooctadiene; $\mathrm{Cy}=$ cyclohexyl; $\mathrm{Py}=$ pyridine), which forms the active polarization transfer catalyst fac,cis- $\left[\operatorname{Ir}(\mathrm{H})_{2}\left(\mathrm{PCy}_{3}\right)(\mathrm{Py})_{3}\right]\left[\mathrm{BF}_{4}\right]$ upon the addition of $p-\mathrm{H}_{2}$ and pyridine. A study using various phosphine ligands revealed that electronic and steric effects of the ligands play an important role in the signal enhancement that is achieved. For example, phosphines that are sterically bulky and have strong electron-donating capacity (e.g. $\left.\mathrm{PCy}_{3}\right)$ yielded the highest signal enhancement for pyridine. ${ }^{11}$

Duckett et al. hypothesized that SABRE could yield even larger signal enhancements by replacing the phosphines with the even stronger electron-donating $\mathrm{N}$-heterocyclic carbene (NHC) ligands. ${ }^{12}$ They validated this approach for the complex $\left[\operatorname{Ir}(\mathrm{H})_{2}(\mathrm{IMes})(\mathrm{py})_{3}\right]$ (IMes = 1,3-bis(2,4,6-trimethylphenyl)-imidazole-2-ylidine). This IMes ligand yields the best SABRE catalyst for pyridine reported to date, with a 360 -fold increase (at $400 \mathrm{MHz}$ ) in the ortho proton's ${ }^{1} \mathrm{H}-\mathrm{NMR}$ signal strength relative to non-hyperpolarized pyridine. ${ }^{12}$ 

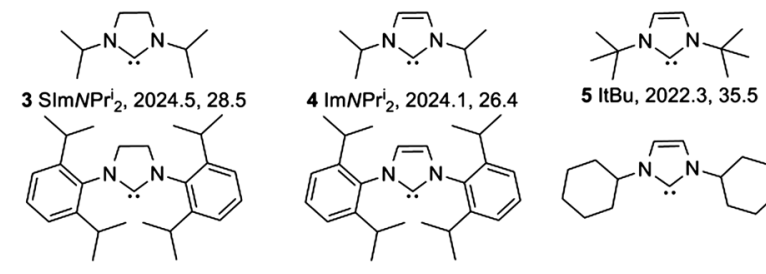

6 SIPr, 2024.9, 35.7 $7 \mathrm{IPr}, 2023.9,33.6$
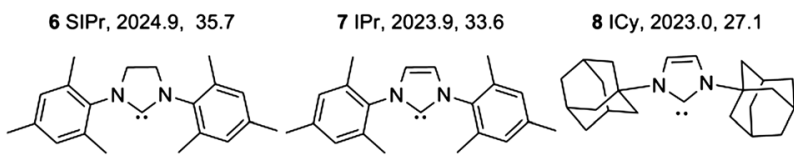

9 SIMes, 2024.6, 32.7

10 IMes, 2023.1, 31.6

11 lad, 2021,6, 36.1

Fig. 2 Ligands used for complex synthesis, compound number, abbreviation, Tolman Electronic Parameter $\left(\mathrm{cm}^{-1}\right)$, buried volume (\%).

We report here on the efficiency of various iridium NHC complexes with aliphatic and aromatic R groups (Fig. 2) ${ }^{13,14}$ as SABRE catalysts. Their steric and electronic properties were quantified by the buried volume $\left(\% V_{\text {bur }}\right)$ and an analogue of the Tolman Electronic Parameter (TEP), respectively. ${ }^{13,15,16}$ To obtain more detailed information regarding the polarization process, we measured the signal enhancement of pyridine and its field dependence for all catalysts. In addition, we determined the lifetime of the complexes by measuring the dissociation rate of pyridine.

In a typical SABRE experiment, a solution of pyridine $(100 \mathrm{mM})$ and $10 \%$ catalyst $(10 \mathrm{mM})$ in deuterated methanol was pressurized with 3 bar $p-\mathrm{H}_{2}(92.5 \%)$ in a prepolarization magnet $(+10$ to -230 Gauss) and subsequently transferred to a $200 \mathrm{MHz}$ NMR instrument where the spectrum was recorded in a single scan. More detailed information on this process can be found in the ESI. $\dagger$ All catalysts were screened, except for catalyst $11 \mathrm{Iad}$, which did not dissolve sufficiently in methanol. The signal enhancements (Fig. 3) were found to be dependent on the prepolarization field. The maximal signal enhancements are obtained at approx. 80 Gauss and varied slightly among the various catalysts (full details are provided in ESI $\dagger$ ). Currently, there is no explanation for the exact position of this optimal prepolarization field.

The highest signal enhancement was obtained with IMes 10, giving enhancements up to 680 at $200 \mathrm{MHz}$ and a prepolarization field of 70 Gauss, corresponding to a polarization value of $1.11 \%$. This complex was also selected by Duckett $e t$ al., who measured an enhancement factor of 360 at $400 \mathrm{MHz}$, which corresponds to a polarization value of $1.16 \%$ and is in reasonable accordance with our result. ${ }^{12}$ Of the other complexes (Fig. 3), the aromatic ones also perform well, but the signal enhancement of the next best catalyst, the saturated analogue SIMes 9, is already significantly lower (369 at 90 Gauss). Signal enhancements dropped below 100 when the aromatic R-group of the NHC ligand was replaced with an alkyl group.

The dependence of the enhancement factor on the electrondonating properties of the various NHC ligands is shown in Fig. 3A. Compared to the Tolman Electronic Parameter range covered by phosphine-type ligands $\left(\sim 20 \mathrm{~cm}^{-1}\right)$, that of NHC is relatively small (less than $3 \mathrm{~cm}^{-1}$ ). For example the unsaturated ligands IMes 10 and IPr 7 are slightly more donating than their saturated counterparts SIMes $\mathbf{9}$ and SIPr $\mathbf{6}$, but there is almost
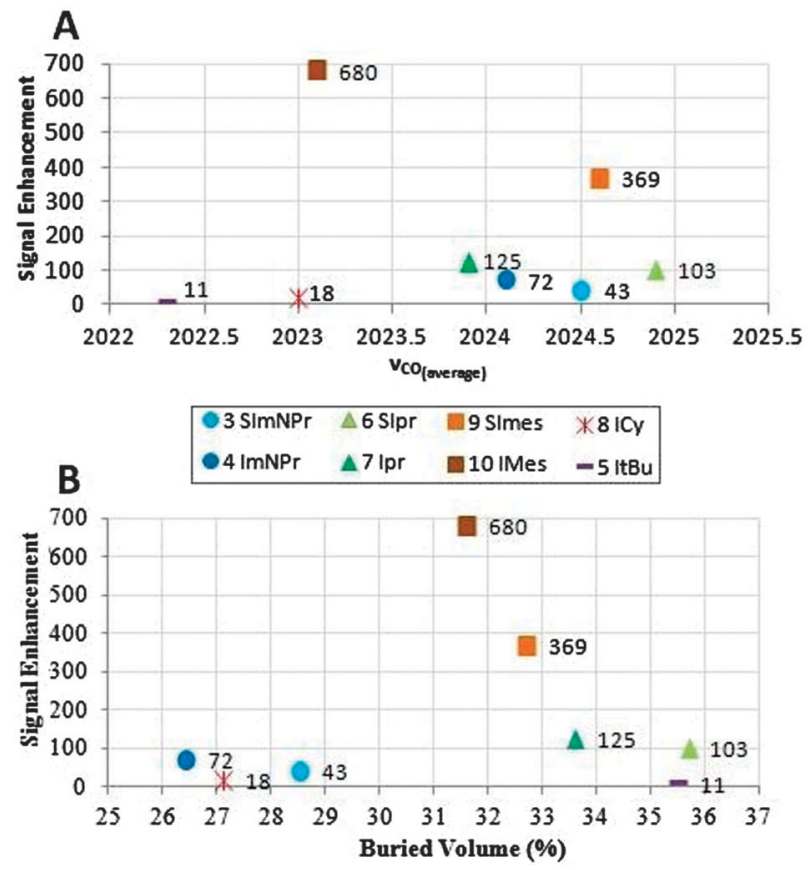

Fig. 3 Maximal obtained signal enhancement versus the modified Tolman Electronic Parameter (A) and steric parameter (buried volume) (B).

no difference in electronics between the two substituent pairs (mesityl and diisopropylphenyl). Therefore, we conclude that electronic effects in the NHC series are relatively weak, and they do not have a strong influence on the enhancement factor.

Fig. 3B depicts the plot of the signal enhancement versus the steric parameter. We conclude from this plot that the unsaturated ligands (I, 4, 7, 10), that have less steric bulk than their respective saturated analogues (SI, 3, 6, 9), yield higher signal enhancements in all cases. Also, an optimal buried volume emerges which yields the highest signal enhancement. In order to determine the effect of the buried volume on the exchange rate $\left(k_{\text {off }}\right)$ of pyridine, selective inversion recovery NMR experiments were performed; with these methodologies slow chemical exchange processes in the range between $10^{-1}$ and $10 \mathrm{~s}^{-1}$ can be studied..$^{17,18}$ Fig. $4 \mathrm{~A}$ reveals that the exchange rate increases with the steric bulk (see ESI $\dagger$ for a complete set of values and errors). The only exception is the tert-butyl substituted ligand $\mathbf{5}$; in this case only a trace amount of active complex is present, because the hydrogenation of cyclooctadiene and dissociation of its product are very slow.

A higher exchange rate of pyridine for the more bulky ligands indicates that the exchange proceeds by a dissociative mechanism, which is in accordance with an earlier thermodynamic and DFT study on 10 IMes alone. ${ }^{12}$ However, the exchange rate is not directly proportional to the observed signal enhancement, as shown in Fig. 4B. The unsaturated ligands have a slightly slower exchange rate and $\% V_{\text {bur }}$ than their saturated ligands, but their signal enhancement is higher. The most efficient complex, IMes 10, has an exchange rate of $10.4 \mathrm{~s}^{-1}$, which is in reasonable agreement with that reported by Duckett et al. $\left(11.7 \mathrm{~s}^{-1}\right){ }^{12}$ On the left side of Fig. 4B (exchange rates below $\left.5.0 \mathrm{~s}^{-1}\right)$, the alkyl substituted NHC's $(3,4,5,8)$ are found, which all have signal enhancements below 100; this means that, 

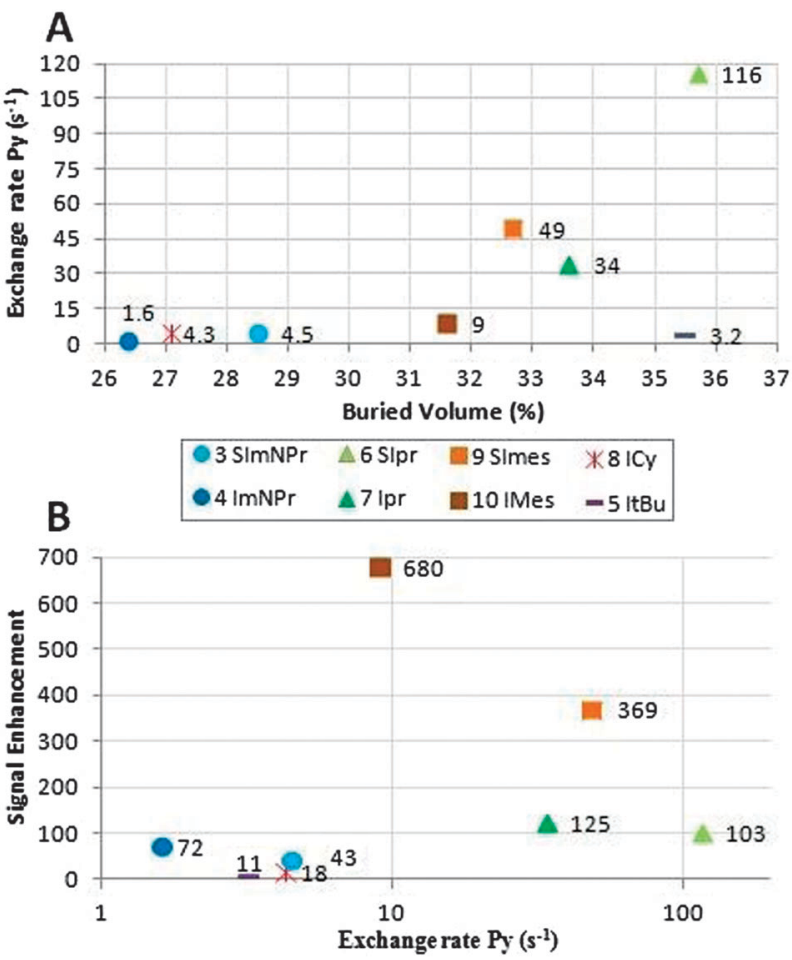

Fig. 4 Exchange rate of pyridine versus buried volume $(A)$ and signal enhancement (B).

at exchange rates half of or less than the optimal value, the signal enhancement drops by an order of magnitude or more. On the other hand, SIMes 9 has a five times higher exchange rate than 10, while the observed signal enhancement is only half of the optimal value. This indicates that a higher exchange rate will only result in a larger signal enhancement if the polarization transfer process is fast enough. When the exchange rate is too low, not enough polarization is built up in the solution and decay occurs due to relaxation processes.

It is of interest to consider the chemical shifts of the ortho protons of the pyridines in the position trans to the $\mathrm{H}$ in the complex, which range from values between 7.89 and $8.03 \mathrm{ppm}$ for aromatic $(7,9,10)$ to 8.23 and $8.30 \mathrm{ppm}$ for alkyl $(3,4,8)$ substituents. In contrast to what might be expected, these values do not correlate with the electronic parameters. The upfield shift for the complexes with aromatic NHC substituents indicates that the pyridine ligand is in the shielding zone of these aromatic substituents. This is in line with the parallel orientation of these moieties found in the IMes crystal structure ${ }^{12}$ and is another indication of the important role of the aromatic NHC substituents in the process of polarization transfer for aromatic substrates such as pyridine.

In conclusion we have successfully synthesized a series of NHC-iridium complexes for SABRE and investigated their potential for pyridine hyperpolarization and the dependence of this process on the prepolarization field. By varying the properties of the NHC ligands, we have gained insight into the structural requirements for the polarization transfer process. The variation in electronic properties, as expressed in the TEP, in the NHC complexes is relatively small, and there appears to be no correlation with the pyridine's chemical shift or hyperpolarization.
With the exception of the slowly reacting ItBu 5 , the pyridine exchange rate increases with $\% V_{\text {bur }}$; this is consistent with a dissociative mechanism for the exchange. The complex with IMes 10 has the optimum value for the exchange rate and $\% V_{\mathrm{bur}}$, resulting in the highest enhancement factor. Comparing every unsaturated NHC ligand (I) with its saturated (SI) analogue, the latter is always the bulkier, leading to a higher exchange rate, which nevertheless results in a lower enhancement factor. The property that has the strongest influence on the enhancement factor is the aromatic character of the substituent, which is also reflected in its effect on the pyridine chemical shifts. More research into the exchange rates of $\mathrm{H}$, the exact $J$-coupling network, and the distances between pyridine and hydride ligands is needed for a full understanding of the polarization transfer.

SG, SA, and BB gratefully acknowledge support from Bruker Biospin $\mathrm{GmbH}$ for supplying the para-hydrogen generator (BPHG90) and the para-hydrogen polarizer (BPHP), and especially thank David Kilgour, Jean-Max Tyburn and Joost Lohman. We also thank J. Klankermayer of RWTH Aachen University for helpful discussions and access to his laboratories. AHJT acknowledges support from the Radboud Honours Academy (Faculty of Science); BJAVW, NE, SSW, MT, MCF, and FPTJR thank the European Union and the provinces of Gelderland and Overijssel for support in the EFRO (Europees Fonds voor Regionale Ontwikkeling) Ultrasense NMR project.

\section{Notes and references}

1 C. Bowers and D. Weitekamp, Phys. Rev. Lett., 1986, 57, 2645.

2 R. W. Adams, J. A. Aguilar, K. D. Atkinson, M. J. Cowley, P. I. P. Elliott, S. B. Duckett, G. G. R. Green, I. G. Khazal, J. López-Serrano and D. C. Williamson, Science, 2009, 323, 1708.

3 N. J. Wood, J. A. Brannigan, S. B. Duckett, S. L. Heath and J. Wagstaff, J. Am. Chem. Soc., 2007, 129, 11012.

4 E. B. Dücker, L. T. Kuhn, K. Münnemann and C. Griesinger, J. Magn. Reson., 2012, 214, 159.

5 L. S. Lloyd, R. W. Adams, M. Bernstein, S. Coombes, S. B. Duckett, G. G. R. Green, R. J. Lewis, R. E. Mewis and C. J. Sleigh, J. Am. Chem. Soc., 2012, 134, 12904.

6 S. Glöggler, M. Emondts, J. Colell, R. Müller, B. Blümich and S. Appelt, Analyst, 2011, 136, 1566.

7 S. Glöggler, R. Müller, J. Colell, M. Emondts, M. Dabrowski, B. Blümich and S. Appelt, Phys. Chem. Chem. Phys., 2011, 13, 13759.

8 Q. Gong, A. Gordji-nejad, B. Blümich and S. Appelt, Anal. Chem., 2010, 82, 7078-7082.

9 T. Theis, M. P. Ledbetter, G. Kervern, J. W. Blanchard, P. J. Ganssle, M. C. Butler, H. D. Shin, D. Budker and A. Pines, J. Am. Chem. Soc., 2012, 134, 3987.

10 R. W. Adams, S. B. Duckett, R. A. Green, D. C. Williamson and G. G. R. Green, J. Chem. Phys., 2009, 131, 194505.

11 K. D. Atkinson, M. J. Cowley, P. I. P. Elliott, S. B. Duckett, G. G. R. Green, J. López-Serrano and A. C. Whitwood, J. Am. Chem. Soc., 2009, 131, 13362.

12 M. J. Cowley, R. W. Adams, K. D. Atkinson, M. C. R. Cockett, S. B. Duckett, G. G. R. Green, J. A. B. Lohman, R. Kerssebaum, D. Kilgour and R. E. Mewis, J. Am. Chem. Soc., 2011, 133, 6134.

13 R. A. Kelly III, H. Clavier, S. Giudice, N. M. Scott, E. D. Stevens, J. Bordner, I. Samardjiev, C. D. Hoff, L. Cavallo and S. P. Nolan, Organometallics, 2007, 27, 202.

14 L. D. Vazquez-Serrano, B. T. Owens and J. M. Buriak, Inorg. Chim. Acta, 2006, 359, 2786.

15 H. Clavier and S. P. Nolan, Chem. Commun., 2010, 46, 841.

16 A. Poater, B. Cosenza, A. Correa, S. Giudice, F. Ragone, V. Scarano and L. Cavallo, Eur. J. Inorg. Chem., 2009, 1759.

17 A. D. Bain and J. A. Cramer, J. Phys. Chem., 1993, 97, 3.

18 T. J. Williams, A. D. Kershaw, V. Li and X. Wu, J. Chem. Educ., 2011, 88, 665 . 